Abstracta Iranica Abstracta Iranica

Revue bibliographique pour le domaine irano-aryen

Volume 27 | 2006

Comptes rendus des publications de 2004

\title{
"The Making of a Munshi ». Comparative Studies of South Asia, Africa and the Middle East, 24/2 (2004), pp. 61-72.
}

Maria Szuppe

\section{(2) OpenEdition}

1 Journals

Édition électronique

URL : http://journals.openedition.org/abstractairanica/6031

DOI : 10.4000/abstractairanica.6031

ISSN : 1961-960X

Éditeur :

CNRS (UMR 7528 Mondes iraniens et indiens), Éditions de l'IFRI

Édition imprimée

Date de publication : 15 mai 2006

ISSN : 0240-8910

Référence électronique

Maria Szuppe, « «The Making of a Munshi ». Comparative Studies of South Asia, Africa and the Middle East, 24/2 (2004), pp. 61-72. », Abstracta Iranica [En ligne], Volume 27 | 2006, document 210, mis en ligne le 02 janvier 2007, consulté le 25 septembre 2020. URL : http://journals.openedition.org/ abstractairanica/6031 ; DOI : https://doi.org/10.4000/abstractairanica.6031

Ce document a été généré automatiquement le 25 septembre 2020

Tous droits réservés 


\title{
«The Making of a Munshi ». Comparative Studies of South Asia, Africa and the Middle East, 24/2 (2004), pp. 61-72.
}

\author{
Maria Szuppe
}

Article très intéressant sur la formation et l'étendue des compétences d'un munšì, scribe ou plutôt fonctionnaire d'administration civile, d'après l'exemple de l'Inde moghole, et à partir de sources en persan émanant de représentants de ce groupe professionnel. Des écrits quasi autobiographiques ou à caractère éducatif et moralisateur, par des munšis moghols, sont étudiés ici, notamment la lettre de Chandrabhan "Brahman" (fin $16^{\mathrm{e}} \mathrm{s}$.) à l'attention de son fils, un apprenti munšĭ, qui esquisse une sorte de parcours idéal pour devenir un munš̌ parfait. Par ailleurs, le Taḍkirat al-safar du munšì Nīk Rāy retraçant sous forme d'un récit autobiographique les étapes de l'éducation de cet auteur du $17^{\mathrm{e}} \mathrm{s}$. Plusieurs points d'intérêt se dégagent à la lecture de ce riche article, dont voici les principaux: le caractère éminemment persanophone de l'éducation et de la formation des munšì dans l'Inde moghole; l'existence d'un vrai groupe professionnel hautement qualifié ayant bâti ses propres traditions; l'existence de lignées familiales de munšī (comme celle de Nīk Rāy); les détails sur leur formation, dès le plus jeune âge, et notamment sur les matières et sur les arts à maîtriser (langue et littérature persanes ; la calligraphie ou plus généralement l'écriture, nevissandegī ; la comptabilité, siyāq ; l'épistographie, enšă'; etc.) ; les précisions sur la nature profondément culturelle de cette formation, avec les titres des ouvrages et des maîtres à étudier: en éthique, en art politique, en comptabilité, en art épistolaire, en histoire et en poésie (impressionnante liste des poètes persans et persanophones). Enfin, l'article montre comment, avec le temps, les Hindous étaient de plus en plus représentés parmi les fonctionnaires de l'administration (étant habituellement issus des castes de brahmanes, de khatri ou de kayasthas) pour devenir majoritaires parmi les munšis, après l'an 1700 environ. Il en résulta en Inde moghole une véritable fusion des traditions scribales persano-musulmanes et hindoues. Elle 
aboutit à la création d'une école tout à fait distincte de celles en vigueur en Asie centrale et en Iran, même si toutes trois restent proches. Si, selon les auteurs, le renommé mìr-e munšì Abū'l-Faḍl 'Allāmī (m. 1602) peut en être considéré comme le "grand idéologue", c'est certainement les réformes du système éducatif, notamment la sécularisation du cursus de la madrasa par l'empereur Akbar (r. 1556-1605), qui sont à l'origine de l'engouement massif des Hindous pour la langue et littérature persanes, ouvrant la voie à leur entrée progressive dans les services de l'administration impériale.

INDEX

Thèmes : 4.2.3. Inde musulmane

\section{AUTEURS}

MARIA SZUPPE

CNRS - Paris 